\title{
Stroop Color-Word Interference Test: Normative data for Spanish-speaking pediatric population
}

D. Rivera ${ }^{\mathrm{a}}$, A. Morlett-Paredes ${ }^{\mathrm{b}}$, A.I. Peñalver Guia ${ }^{\mathrm{c}}$, M.J. Irías Escher ${ }^{\mathrm{d}}$, M. Soto-Añari ${ }^{\mathrm{e}}$, A. Aguayo Arelis ${ }^{\mathrm{f}}$, S. Rute-Pérez ${ }^{\mathrm{g}}$, A. Rodríguez-Lorenzana ${ }^{\mathrm{h}}$, Y. Rodríguez-Agudelo $^{\mathrm{i}}$, N. Albaladejo-Blázquezi ${ }^{\mathrm{j}}$ C. García de la Cadena ${ }^{\mathrm{k}}$, J.A. Ibáñez-Alfonsol, W. Rodriguez-Irizarry ${ }^{\mathrm{m}}$, C.E. García-Guerreron ${ }^{n}$ I.D. Delgado-Mejía ${ }^{\circ}$, A. Padilla-López ${ }^{\mathrm{p}}$, E. Vergara-Moragues $^{\mathrm{q}}$, M.D. Barrios Nevador ${ }^{\mathrm{r}}$, M. Saracostti Schwartzman ${ }^{\mathrm{s}}$ and J.C. Arango-Lasprilla ${ }^{\mathrm{a}, \mathrm{t}, *}$

${ }^{a}$ BioCruces Health Research Institute, Cruces University Hospital, Barakaldo, Spain

${ }^{\mathrm{b}}$ Department of Psychology, Virginia Commonwealth University, Richmond, USA

${ }^{\mathrm{c}}$ National Institute of Neurology and Neurosurgery INN, Havana, Cuba

${ }^{\mathrm{d}}$ Escuela de Ciencias Psicológicas, Universidad Nacional Autónoma de Honduras, Tegucigalpa, Honduras

${ }^{\mathrm{e}}$ Universidad Católica San Pablo, Arequipa, Peru

${ }^{\mathrm{f}}$ Departamento de investigación, Psicología, Universidad Enrique Díaz de León, Guadalajara, Mexico ${ }^{\mathrm{g}}$ CIMCYC-The Mind, Brain and Behaviour Research Centre, Universidad de Granada, Granada, Spain

${ }^{\mathrm{h}}$ Escuela de Psicología, Universidad de Las Américas, Quito, Ecuador

instituto Nacional de Neurología y Neurocirugía, MVS, Ciudad de México, Mexico

${ }^{\mathrm{j}}$ Department of Health Psychology, University of Alicante, Spain

${ }^{\mathrm{k}}$ Departamento de Psicología, Universidad del Valle de Guatemala, Guatemala City, Guatemala

${ }^{1}$ Department of Psychology, Universidad Loyola Andalucía, Sevilla, Spain.

${ }^{\mathrm{m}}$ Universidad Interamericana de Puerto Rico, Recinto de San Germán, Puerto Rico

${ }^{\mathrm{n}}$ Mindpedia Centro de Psicología Avanzada, Monterrey, México.

${ }^{\circ}$ Universidad Autónoma de Asunción (UAA), Asunción, Paraguay

${ }^{\mathrm{p}}$ Laboratorio de Psicofisiología, Facultad de Ciencias Humanas, Universidad Autónoma de Baja California, Mexicali, Mexico

${ }^{\mathrm{q}}$ Universidad Internacional de la Rioja (UNIR), Logroño, Spain

${ }^{\mathrm{r}}$ Research Center CERNEP, Almeria University, Almería, Spain

${ }^{\mathrm{s}}$ Universidad de la Frontera, Temuco, Chile

${ }^{\mathrm{t}}$ IKERBASQUE, Basque Foundation for Science, Bilbao, Spain

\begin{abstract}
.
OBJECTIVE: To generate normative data for the Stroop Word-Color Interference test in Spanish-speaking pediatric populations.

METHOD: The sample consisted of 4,373 healthy children from nine countries in Latin America (Chile, Cuba, Ecuador, Guatemala, Honduras, Mexico, Paraguay, Peru, and Puerto Rico) and Spain. Each participant was administered the Stroop Word-Color Interference test as part of a larger neuropsychological battery. The Stroop Word, Stroop Color, Stroop WordColor, and Stroop Interference scores were normed using multiple linear regressions and standard deviations of residual values. Age, age ${ }^{2}$, sex, and mean level of parental education (MLPE) were included as predictors in the analyses.
\end{abstract}

*Address for correspondence: Juan Carlos Arango Lasprilla, Ph.D., BioCruces Health Research Institute. Cruces University Hospital, IKERBASQUE. Basque Foundation for Science, Plaza de Cruces s/n. 48903, Barakaldo. Bizkaia, Spain. Tel.: +34 946006000/Ext. 7963; E-mail: jcalasprilla@gmail.com. 
RESULTS: The final multiple linear regression models showed main effects for age on all scores, except on Stroop Interference for Guatemala, such that scores increased linearly as a function of age. Age ${ }^{2}$ affected Stroop Word scores for all countries, Stroop Color scores for Ecuador, Mexico, Peru, and Spain; Stroop Word-Color scores for Ecuador, Mexico, and Paraguay; and Stroop Interference scores for Cuba, Guatemala, and Spain. MLPE affected Stroop Word scores for Chile, Mexico, and Puerto Rico; Stroop Color scores for Mexico, Puerto Rico, and Spain; Stroop Word-Color scores for Ecuador, Guatemala, Mexico, Puerto Rico and Spain; and Stroop-Interference scores for Ecuador, Mexico, and Spain. Sex affected Stroop Word scores for Spain, Stroop Color scores for Mexico, and Stroop Interference for Honduras.

CONCLUSIONS: This is the largest Spanish-speaking pediatric normative study in the world, and it will allow neuropsychologists from these countries to have a more accurate approach to interpret the Stroop Word-Color Interference test in pediatric populations.

Keywords: Stroop Word-Color Interference test, neuropsychology, Spanish-speaking populations, pediatric population

\section{Introduction}

The Stroop Color-Word Interference Test is the well-known instrument to study response interference and inhibition in children and adults, and was first introduced in 1935 by John Ridley Stroop (Stroop, 1935). The original Stroop Test (Stroop, 1935) is now out of print, but since then numerous versions of the test have been developed including the Comalli (Comalli, Wapner, \& Werner, 1962), the Dodrill (Dodrill, 1978), the Golden (Golden \& Freshwater, 2002), the Number-Stroop paradigm (Tzelgov, Meyer, \& Henik, 1992) and the Victoria (Regard, 1984) versions. The original Stroop Test and all current variations consist of three conditions: a word task, a color task, and a color-word task. The word task is a sheet of papper with a list of words for colors (e.g. "red", "green", and "blue") printed in black ink; in the color task there are groups of four X's ("XXXX") printed in the same colors listed on the word page; and the color-word sheet is a list of those same color words printed in opposite colors (e.g., the word "red" might be printed in the color "green"; Golden, 2007). However, these different versions tend to vary on the use of "XXXs", the number of items per task, the number and choice of colors used, inclusion of a fourth task with words printed in matching colors, and the elimination of word or color task (Strauss, Sherman, \& Spreen, 2006).

In neuropsychology, the Stroop Test has been traditionally used as a measure of executive functioning (Lezak, 1995; Spreen \& Strauss, 1998). The three conditions to the Stroop test are thought to measure different aspects of executive functioning. The word and color tasks are believed to reveal processing speed and may be affected by speech motor problems or learning disabilities (Golden, EspePfiefer, \& Wachlser-Felder, 2000). In the color task, performance may be affected by speech motor function or an individual's inability to name colors, or colorblindness. The Stroop color-word task has been found to measure selective attention, cognitive flexibility information, and cognitive inhibition (Rosselli et al., 2002; Strauss et al., 2006; Van der Elst, Van Boxtel, Van Breukelen, \& Jolles, 2006; Wecker, Kramer, Wisniewski, Delis, \& Kaplan, 2000).

Performance on the Stroop Test is sensitive to dysfunction of the inferior frontal, dorsolateral prefrontal, and anterior cingulated cortices (Egner \& Hirsch, 2005; Harrison et al., 2005), including neuropsychiatric disturbances. Within the pediatric literature, the Stroop Test has been used to assess executive dysfunctions in several children illness groups, including Traumatic Brain Injury (Max et al., 2013), benign focal childhood epilepsy (Kernan et al., 2012), leukemia (Kim et al., 2015), Attention Deficit Hyperactivity Disorder (Assef, Capovilla, \& Capovilla, 2007; Chang, Liu, Yu, \& Lee, 2012), autism (Lai et al., 2016), learning disabilities (Westendorp, Hartman, Houwen, Smith, \& Visscher, 2014), as well as prenatal exposure to alcohol, cocaine and tobacco (Gautam, Warner, Kan, \& Sowell, 2015; Lebel et al., 2013).

In general, normative studies with different populations are important because cultural and demographic variables can impact cognitive function and its development and measurement (Ardila, 2007). For example, some cognitive functions in the Stroop Test can be influenced by several variables during development, such as, age, socioeconomic status, level of parental education, and language (e.g. bilingualism; Armengol, 2002; Bialystok, Luk, Peets, \& Yang, 2010; Esposito, Baker-Ward, \& Mueller, 2013; Faccioli, Peru, Rubini, \& Tassinari, 2008; Farah et al., 2006; Oliveira, Mograbi, Gabrig, \& CharchatFichman, 2016). These factors may be especially important in the evaluation of children because language and cultural influences may moderate the speed, pattern, and style of cognitive development as well as the likelihood of suffering a developmental disorder (Paulesu et al., 2001). 
The number of normative studies of neuropsychological measures, including the Stroop Tests with Latin American and Spanish samples has been growing in recent years (Rivera et al., 2015; Rognoni et al., 2013), but few studies have developed normative data for children. Currently, only a number of countries have generated normative studies for the Stroop Test within the pediatric population, including but not limited to Brazil (Oliveira et al., 2016), China (Lee, Yuen, \& Chan, 2002), Italy (Barbarotto et al., 1998), México (Armengol, 2002), Portugal (Martins et al., 2005) and the U.S. (Moran \& Yates, 2011). Regarding the availability of the Stroop Test and normative data for use with Latin American and Spanish pediatric populations, the majorities of the instruments used are adaptations of North American tests and standardized with American norms (Ferraro, 2015; Razani, Burciaga, Madore, \& Wong, 2007). This situation has tremendous impact on the growing field of neuropsychology, especially when one considers the heterogeneity of the Latin American and Spanish population with regard to culture and education. Comparison normative data (e.g. for the Stroop Test) among different stages of development and cultures may help understand the sociobiological bases of behavior and, eventually, how they change the functional organization of the brain (CastroCaldas, Petersson, Reis, Stone-Elander, \& Ingvar, 1998).

Appropriate normative data are needed for the Stroop Test in order to assess executive function correctly in other countries outside of the United States. To date, only limited normative data have been developed for the Stroop Test in pediatric samples. Thus, the objective of this paper is to generate normative data for children from nine Spanish-speaking countries in Latin America and Spain. Clinicians and researchers need to be cautious when using the Stroop Test with children from other cultures as the interpretation of the children's performance from Latin America and Spain using norms from other countries and languages might result in significant errors in assessment.

\section{Method}

\subsection{Participants}

The sample consisted of 4,373 healthy children who were recruited from Chile, Cuba, Ecuador, Guatemala, Honduras, Mexico, Paraguay, Peru,
Puerto Rico, and Spain. Participants were selected according to the following criteria: a) were between 6 and 17 years of age, b) were born and currently lived in the country where the study was conducted, c) spoke Spanish as their mother tongue, d) an IQ $\geq 80$ on the Test Of Non-verbal Intelligence (TONI-2, Brown, Sherbenou, \& Johnsen, 2009), and e) a score $<19$ on the Children's Depression Inventory (CDI, Kovacs, 1992).

Children with history of neurologic or psychiatric disorders, as reported by the participant's parent(s), were excluded due to its effects on cognitive performance. Participants in the study were recruited from public and private schools, and signed an informed consent. Socio-demographic and participant characteristics for each of the countries' samples have been reported elsewhere (Rivera \& Arango-Lasprilla, 2017). Ethics Committee approval was obtained for the study in each country.

\subsection{Instrument administration}

The Stroop Color-Word Interference Test consists of three pages, each with 100 components randomly organized into five columns. In the first page the participant must read aloud the words "Red", "Green", and "Blue" printed in black ink. In the second one, "color naming", the color (blue, green or red) of each element "XXXX" must be named. And in the last one, "interference", the task is to name the color of the ink, inhibiting the reading of the word, which corresponds to the name of another color. The subject has 45 seconds to read aloud, as quickly as possible, the columns from left to right. Finally, the Interference Index was calculated with the formula: $\mathrm{WC}-[(\mathrm{W} \times \mathrm{C}) /(\mathrm{W}+\mathrm{C})]$, and indicates the degree to which the person has control over interference (Golden, 2007).

\subsection{Statistical analyses}

Detailed statistical analyses used to generate the normative data for the Stroop Color-Word Interference test scores are described in Rivera \& Arango-Lasprilla (2017). In summary, the scores were standardized using multiple linear regression analyses by means of a four-step procedure. 1) First, the Words, Color, Word-Color, and Interference scores were computed separately by means of the final multiple regression models. The full regression models included as predictors: age, age ${ }^{2}$, sex, and mean level of parental education (MLPE). Age 
was centered (=calendar age - mean age in the sample by country) before computing the quadratic age term to avoid multicollinearity (Aiken \& West, 1991). Sex was coded as male $=1$ and female $=0$. The MLPE variable was coded as 1 if the participant's parent(s) had $>12$ years of education or 0 if participant's parent(s) had $\leq 12$ years of education. If predicted variables were not statistically significant in the multivariate model with an alpha of 0.05 , the non-significant variables were removed and the model was run again. A final regression model was conducted $\hat{y}_{i}=\mathrm{B}_{0}+\mathrm{B}_{1} \cdot\left(\text { Age }-\bar{x}_{\text {Age by country }}\right)_{i}+\mathrm{B}_{2}$. $\left(\text { Age }-\bar{x}_{\text {Age by country }}\right)_{i}^{2}+\mathrm{B}_{3} \cdot \operatorname{Sex}_{i}+\mathrm{B}_{4} \cdot M L P E_{i}$. 2) Residual scores $\left(e_{i}\right)$ were calculated based on the final model $\left.\left(e_{i}=y_{i}-\hat{y}_{i}\right) .3\right)$ Residuals were standardized using the residual Standard Deviation $\left(S D_{e}\right)$ value provided by the regression model: $z_{i}=e_{i} / S D_{e} .4$ ) Standardized residuals were converted to percentile values using the standard normal cumulative distribution function. This four-step process was applied for Words, Color, Word-Color, and Interference scores separately for each country.

For all multiple linear regression models, the following assumptions were evaluated: a) multicollinearity by the values of the Variance Inflation Factor (VIF), which must not exceed 10, and the collinearity tolerance values, which must not exceed the value of 1 (Kutner, Nachtsheim, Neter, \& $\mathrm{Li}, 2005)$, and b) the existence of influential values by calculating the Cook's distance. The maximum Cook's distance value was related to a $F(p, n-p)$ distribution. Influential values are considered when percentile value is equal or higher than 50 (Cook, 1977; Kutner et al., 2005). All analyzes were performed using SPSS version 23 (IBM Corp., Armonk, NY).

\section{Results}

\subsection{Stroop Word}

The final multivariate linear regression models for the ten country-specific Stroop Word score were significant (see Table 1). In all countries, the Stroop Word score increased linearly as a function of age. The Stroop Word score for all countries was affected by a quadratic age effect. Children from Chile, Mexico, and Puerto Rico whose parent(s) had a MLPE $>12$ years obtained higher Stroop Word score than children whose parent(s) had a MLPE $\leq 12$ years.
The child's sex affected Stroop Word score for Spain such that girls scored higher than boys. The amount of variance these predictors explained in the Stroop Word score ranged from 26.3\% (in Paraguay) to 63.8 (in Spain).

\subsection{Stroop Color}

The final multivariate linear regression models for the ten country-specific Stroop Color score were significant (see Table 2). In all countries, the Stroop Color score increased linearly as a function of age. The Stroop Color score for Ecuador, Mexico, Peru, and Spain was affected by a quadratic age effect. Children from Mexico, Puerto Rico, and Spain whose parent(s) had a MLPE $>12$ years obtained higher Stroop Color score than children whose parent(s) had a MLPE $\leq 12$ years. The child's sex affected Stroop Color score for Mexico, such that boys scored higher than girls. The amount of variance these predictors explained in the Stroop Color score ranged from $20.2 \%$ (in Paraguay) to $53.4 \%$ (in Spain).

\subsection{Stroop Word-Color}

The final multivariate linear regression models for the ten country-specific Stroop Word-Color score were significant (see Table 3). In all countries, the Stroop Word-Color score increased linearly as a function of age. The Stroop Word-Color scores for Ecuador, Mexico, and Paraguay were affected by a quadratic age effect. Children from Ecuador, Guatemala, Mexico, Puerto Rico, and Spain whose parent(s) had a MLPE $>12$ years obtained higher Stroop Word-Color scores than children whose parent(s) had a MLPE $\leq 12$ years. The child's sex did not affect Stroop Word-Color scores for any country. The amount of variance these predictors explained in the Stroop Word-Color scores ranged from $26.5 \%$ (in Guatemala) to $51.8 \%$ (in Spain).

\subsection{Stroop Interference Index}

The final multivariate linear regression models for the ten country-specific Stroop Interference score were significant (see Table 4). In all countries except in Guatemala, the Stroop Interference score increased linearly as a function of age. The Stroop Interference score for Cuba, Guatemala, and Spain was affected by a quadratic age effect. Children from Ecuador, Mexico, and Spain whose parent(s) had a MLPE $>12$ years 
Table 1

Final multiple linear regression models for Stroop Word scores

\begin{tabular}{|c|c|c|c|c|c|c|}
\hline$\overline{\text { Country }}$ & $\mathrm{B}$ & Std. Error & $t$ & Sig. & $R^{2}$ & $S D e$ (residual) \\
\hline \multicolumn{7}{|l|}{ Chile } \\
\hline Constant & 79.673 & 1.249 & 63.807 & $<0.001$ & \multirow{4}{*}{0.565} & \multirow[t]{4}{*}{13.729} \\
\hline Age & 4.684 & 0.227 & 20.632 & $<0.001$ & & \\
\hline $\mathrm{Age}^{2}$ & -0.295 & 0.074 & -3.983 & $<0.001$ & & \\
\hline MLPE & 4.368 & 1.587 & 2.752 & $<0.001$ & & \\
\hline \multicolumn{7}{|l|}{ Cuba } \\
\hline Constant & 82.302 & 0.935 & 88.037 & $<0.001$ & \multirow[t]{3}{*}{0.629} & \multirow[t]{3}{*}{11.908} \\
\hline Age & 4.365 & 0.178 & 24.483 & $<0.001$ & & \\
\hline $\mathrm{Age}^{2}$ & -0.308 & 0.059 & -5.267 & $<0.001$ & & \\
\hline \multicolumn{7}{|l|}{ Ecuador } \\
\hline Constant & 84.446 & 1.250 & 67.567 & $<0.001$ & \multirow[t]{3}{*}{0.536} & \multirow[t]{3}{*}{13.967} \\
\hline Age & 4.372 & 0.241 & 18.131 & $<0.001$ & & \\
\hline $\mathrm{Age}^{2}$ & -0.300 & 0.080 & -3.723 & $<0.001$ & & \\
\hline \multicolumn{7}{|l|}{ Guatemala } \\
\hline Constant & 76.070 & 1.167 & 65.197 & $<0.001$ & \multirow[t]{3}{*}{0.399} & \multirow[t]{3}{*}{12.861} \\
\hline Age & 4.595 & 0.413 & 11.123 & $<0.001$ & & \\
\hline Age $^{2}$ & -0.313 & 0.125 & -2.512 & 0.013 & & \\
\hline \multicolumn{7}{|l|}{ Honduras } \\
\hline Constant & 74.259 & 1.298 & 57.223 & $<0.001$ & \multirow[t]{3}{*}{0.361} & \multirow[t]{3}{*}{15.169} \\
\hline Age & 3.696 & 0.293 & 12.603 & $<0.001$ & & \\
\hline Age $^{2}$ & -0.206 & 0.094 & -2.204 & 0.028 & & \\
\hline \multicolumn{7}{|l|}{ Mexico } \\
\hline Constant & 77.753 & 0.944 & 82.327 & $<0.001$ & \multirow[t]{4}{*}{0.480} & \multirow[t]{4}{*}{14.626} \\
\hline Age & 4.193 & 0.152 & 27.561 & $<0.001$ & & \\
\hline $\mathrm{Age}^{2}$ & -0.334 & 0.050 & -6.671 & $<0.001$ & & \\
\hline MLPE & 6.443 & 1.011 & 6.375 & $<0.001$ & & \\
\hline \multicolumn{7}{|l|}{ Paraguay } \\
\hline Constant & 76.043 & 1.954 & 38.922 & $<0.001$ & \multirow[t]{3}{*}{0.263} & \multirow[t]{3}{*}{20.462} \\
\hline Age & 3.805 & 0.397 & 9.579 & $<0.001$ & & \\
\hline $\mathrm{Age}^{2}$ & -0.489 & 0.138 & -3.547 & $<0.001$ & & \\
\hline \multicolumn{7}{|l|}{ Peru } \\
\hline Constant & 84.157 & 1.115 & 75.471 & $<0.001$ & \multirow[t]{3}{*}{0.607} & 13.185 \\
\hline Age & 4.505 & 0.234 & 19.238 & $<0.001$ & & \\
\hline $\mathrm{Age}^{2}$ & -0.409 & 0.077 & -5.314 & $<0.001$ & & \\
\hline Puerto Rico & & & & & & \\
\hline Constant & 66.464 & 3.526 & 18.851 & $<0.001$ & 0.392 & 19.714 \\
\hline Age & 3.617 & 0.456 & 7.932 & $<0.001$ & & \\
\hline $\mathrm{Age}^{2}$ & -0.432 & 0.153 & -2.824 & 0.005 & & \\
\hline MLPE & 16.596 & 3.492 & 4.752 & $<0.001$ & & \\
\hline Spain & & & & & & \\
\hline Constant & 91.125 & 0.711 & 128.206 & $<0.001$ & 0.638 & 12.625 \\
\hline Age & 5.012 & 0.122 & 41.120 & $<0.001$ & & \\
\hline Age $^{2}$ & -0.360 & 0.039 & -9.159 & $<0.001$ & & \\
\hline Sex & -2.567 & 0.806 & -3.183 & 0.002 & & \\
\hline
\end{tabular}

Note. MLPE: Mean level of parental education.

obtained higher Stroop Interference score than children whose parent(s) had a MLPE $\leq 12$ years. The child's sex only affected Stroop Interference score for Honduras. The amount of variance these predictors explained in the Stroop Interference score ranged from $2.8 \%$ (in Guatemala) to $15.6 \%$ (in Paraguay).

The assumptions of multiple linear regression analysis were met for all final models. There was not multicollinearity (the VIF values were below 10; VIF $\leq 1.116$; collinearity tolerance values did not exceed the value of 1) or influential cases (the maximum
Cook's distance value was 0.154 in a $F_{(2,298)}$ distribution which correspond to percentile 14).

\subsection{Normative procedure}

Norms (e.g., a percentile score) for the different Stroop Color-Word Interference Test scores by country were established using the four-step procedure described in the statistical analysis section. An example will be provided to facilitate an improved understanding of the procedure used to obtain the 
Table 2

Final multiple linear regression models for Stroop Color scores

\begin{tabular}{|c|c|c|c|c|c|c|}
\hline Country & $\mathrm{B}$ & Std. Error & $t$ & Sig. & $R^{2}$ & $S D e$ (residual) \\
\hline \multicolumn{7}{|l|}{$\overline{\text { Chile }}$} \\
\hline Constant & 56.763 & 0.636 & 89.196 & $<0.001$ & \multirow[t]{2}{*}{0.453} & \multirow[t]{2}{*}{11.684} \\
\hline Age & 3.146 & 0.188 & 16.732 & $<0.001$ & & \\
\hline \multicolumn{7}{|l|}{ Cuba } \\
\hline Constant & 58.409 & 0.655 & 89.125 & $<0.001$ & \multirow[t]{2}{*}{0.516} & \multirow[t]{2}{*}{12.657} \\
\hline Age & 3.771 & 0.189 & 19.929 & $<0.001$ & & \\
\hline \multicolumn{7}{|l|}{ Ecuador } \\
\hline Constant & 56.723 & 0.863 & 65.706 & $<0.001$ & \multirow[t]{3}{*}{0.528} & \multirow[t]{3}{*}{9.648} \\
\hline Age & 2.988 & 0.167 & 17.940 & $<0.001$ & & \\
\hline $\mathrm{Age}^{2}$ & -0.145 & 0.056 & -2.606 & 0.010 & & \\
\hline \multicolumn{7}{|l|}{ Guatemala } \\
\hline Constant & 52.382 & 0.772 & 67.813 & $<0.001$ & \multirow[t]{2}{*}{0.283} & \multirow[t]{2}{*}{10.619} \\
\hline Age & 2.816 & 0.327 & 8.614 & $<0.001$ & & \\
\hline \multicolumn{7}{|l|}{ Honduras } \\
\hline Constant & 51.003 & 0.598 & 85.266 & $<0.001$ & \multirow[t]{2}{*}{0.433} & \multirow[t]{2}{*}{10.079} \\
\hline Age & 2.776 & 0.189 & 14.688 & $<0.001$ & & \\
\hline \multicolumn{7}{|l|}{ Mexico } \\
\hline Constant & 53.320 & 0.766 & 69.599 & $<0.001$ & \multirow[t]{5}{*}{0.462} & \multirow[t]{5}{*}{10.582} \\
\hline Age & 2.940 & 0.110 & 26.681 & $<0.001$ & & \\
\hline $\mathrm{Age}^{2}$ & -0.163 & 0.036 & -4.506 & $<0.001$ & & \\
\hline MLPE & 4.408 & 0.732 & 6.026 & $<0.001$ & & \\
\hline Sex & 1.608 & 0.726 & 2.213 & 0.027 & & \\
\hline \multicolumn{7}{|l|}{ Paraguay } \\
\hline Constant & 54.117 & 0.872 & 62.090 & $<0.001$ & \multirow[t]{2}{*}{0.202} & \multirow[t]{2}{*}{14.001} \\
\hline Age & 2.131 & 0.262 & 8.135 & $<0.001$ & & \\
\hline \multicolumn{7}{|l|}{ Peru } \\
\hline Constant & 57.988 & 1.013 & 57.228 & $<0.001$ & \multirow[t]{3}{*}{0.425} & \multirow[t]{3}{*}{11.981} \\
\hline Age & 2.947 & 0.213 & 13.847 & $<0.001$ & & \\
\hline $\mathrm{Age}^{2}$ & -0.174 & 0.070 & -2.490 & 0.013 & & \\
\hline \multicolumn{7}{|l|}{ Puerto Rico } \\
\hline Constant & 47.363 & 1.982 & 23.893 & $<0.001$ & \multirow[t]{3}{*}{0.407} & 13.012 \\
\hline Age & 3.014 & 0.285 & 10.563 & $<0.001$ & & \\
\hline MLPE & 7.035 & 2.297 & 3.062 & 0.003 & & \\
\hline Spain & & & & & & \\
\hline Constant & 58.618 & 0.661 & 88.682 & $<0.001$ & 0.534 & 10.287 \\
\hline Age & 3.343 & 0.101 & 33.101 & $<0.001$ & & \\
\hline $\mathrm{Age}^{2}$ & -0.097 & 0.033 & -2.994 & 0.003 & & \\
\hline MLPE & 1.988 & 0.695 & 2.861 & 0.004 & & \\
\hline
\end{tabular}

Note. MLPE: Mean level of parental education.

percentile associated with a score on this test. Let's assume we need to find the percentile score for an 8 -year-old Guatemalan girl who scored a 39 on the Stroop Color and whose parent(s) have a mean of 10 years of education (MLPE). The steps to obtain the percentile for this score are: 1) Find Guatemala in Table 2, which provides the final regression models by country for the Stroop Color score. Use the $\mathrm{B}$ weights to create an equation that will allow you to obtain the predicted Stroop Color score for this child using the coding provided in the statistical analysis section. The corresponding B weights are multiplied by the centered age (=calendar age mean age in the Guatemalan sample which is equal to 10.7 years). $\mathrm{Age}^{2}$, sex, and MLPE were not significant predictors, and therefore are not included in this model. See Rivera \& Arango-Lasprilla (2017) to figure out the mean age of each country's sample. Then the result is added to the constant generated by the model in order to calculate the predicted value.

In the case of the Guatemalan girl, the predicted Stroop Color score would be calculated using the following equation: $\hat{y}_{i}=52.382+\left[2.816 \cdot\left(\right.\right.$ Age $_{i}-$ $10.7)]$. The girl's age is 8 . Thus, the predicted value equation is: $\hat{y}_{i}=52.382+[2.816 \cdot(8-10.7)]=$ $52.382+(-7.604)=44.778$. 2) In order to calculate the residual value (indicated with an $e_{i}$ in the equation), we subtract the actual Stroop Color score (she scored 39) from the predicted value we just calculated $\left(e_{i}=y_{i}-\hat{y}_{i}\right)$. In this case, it would be $e_{i}=$ $39-44.778=-5.778$. 3) Next, consult the $S D_{e}$ 
Table 3

Final multiple linear regression models for Stroop Word-Color scores

\begin{tabular}{|c|c|c|c|c|c|c|}
\hline Country & $\mathrm{B}$ & Std. Error & $t$ & Sig. & $R^{2}$ & $\overline{S D e}$ (residual) \\
\hline \multicolumn{7}{|l|}{ Chile } \\
\hline Constant & 35.104 & 0.540 & 65.020 & $<0.001$ & \multirow[t]{2}{*}{0.451} & \multirow[t]{2}{*}{9.913} \\
\hline Age & 2.658 & 0.160 & 16.662 & $<0.001$ & & \\
\hline \multicolumn{7}{|l|}{ Cuba } \\
\hline Constant & 34.312 & 0.510 & 67.214 & $<0.001$ & \multirow[t]{2}{*}{0.458} & \multirow[t]{2}{*}{9.859} \\
\hline Age & 2.614 & 0.147 & 17.737 & $<0.001$ & & \\
\hline \multicolumn{7}{|l|}{ Ecuador } \\
\hline Constant & 31.592 & 1.081 & 29.232 & $<0.001$ & \multirow[t]{4}{*}{0.515} & \multirow[t]{4}{*}{8.200} \\
\hline Age & 2.453 & 0.142 & 17.216 & $<0.001$ & & \\
\hline $\mathrm{Age}^{2}$ & -0.096 & 0.047 & -2.030 & 0.043 & & \\
\hline MLPE & 2.827 & 1.103 & 2.563 & 0.011 & & \\
\hline \multicolumn{7}{|l|}{ Guatemala } \\
\hline Constant & 28.226 & 0.661 & 42.677 & $<0.001$ & \multirow[t]{3}{*}{0.265} & \multirow[t]{3}{*}{7.961} \\
\hline Age & 1.848 & 0.248 & 7.446 & $<0.001$ & & \\
\hline MLPE & 3.339 & 1.401 & 2.383 & 0.018 & & \\
\hline \multicolumn{7}{|l|}{ Honduras } \\
\hline Constant & 29.179 & 0.477 & 61.202 & $<0.001$ & \multirow[t]{2}{*}{0.436} & \multirow[t]{2}{*}{8.033} \\
\hline Age & 2.227 & 0.151 & 14.787 & $<0.001$ & & \\
\hline \multicolumn{7}{|l|}{ Mexico } \\
\hline Constant & 32.756 & 0.567 & 57.721 & $<0.001$ & \multirow{4}{*}{0.450} & \multirow{4}{*}{8.788} \\
\hline Age & 2.384 & 0.091 & 26.073 & $<0.001$ & & \\
\hline $\mathrm{Age}^{2}$ & -0.112 & 0.030 & -3.729 & $<0.001$ & & \\
\hline MLPE & 3.655 & 0.607 & 6.018 & $<0.001$ & & \\
\hline \multicolumn{7}{|l|}{ Paraguay } \\
\hline Constant & 34.773 & 0.984 & 35.334 & $<0.001$ & \multirow[t]{3}{*}{0.394} & \multirow[t]{3}{*}{10.307} \\
\hline Age & 2.594 & 0.200 & 12.968 & $<0.001$ & & \\
\hline $\mathrm{Age}^{2}$ & -0.153 & 0.069 & -2.202 & 0.029 & & \\
\hline \multicolumn{7}{|l|}{ Peru } \\
\hline Constant & 33.777 & 0.502 & 67.325 & $<0.001$ & \multirow[t]{2}{*}{0.483} & \multirow[t]{2}{*}{8.863} \\
\hline Age & 2.596 & 0.152 & 17.071 & $<0.001$ & & \\
\hline \multicolumn{7}{|l|}{ Puerto Rico } \\
\hline Constant & 29.208 & 1.327 & 22.017 & $<0.001$ & \multirow{3}{*}{0.437} & 8.708 \\
\hline Age & 2.152 & 0.191 & 11.269 & $<0.001$ & & \\
\hline MLPE & 4.721 & 1.538 & 3.071 & 0.002 & & \\
\hline Spain & & & & & & \\
\hline Constant & 34.670 & 0.464 & 74.796 & $<0.001$ & 0.518 & 8.586 \\
\hline Age & 2.682 & 0.084 & 31.998 & $<0.001$ & & \\
\hline MLPE & 2.136 & 0.580 & 3.685 & $<0.001$ & & \\
\hline
\end{tabular}

Note. MLPE: Mean level of parental education.

column in Table 2 to obtain the country-specific $S D_{e}$ (residual) value. For Guatemala it is 10.619 . Using this value, we can transform the residual value to a standardized $z$ score using the equation $z_{i}=e_{i} / S D_{e}$. In this case, we have $-5.778 / 10.619=-0.544$. This is the standardized $z$ score for a 8-year-old Guatemalan girl who scored a 39 on the Stroop Color who has parents with 10 years of education (MLPE). 4) The last step is to use the tables available in most statistical reference books (e.g., Strauss et al., 2006). In this example, the $z$ score (probability) of -0.544 corresponds to the $29^{\text {th }}$ percentile. It is important to remember to use the appropriate tables that correspond to each test (Stroop Color, Word, WordColor, and Interference) when performing these calculations.

\subsection{User-friendly normative data}

The four-step normative procedures explained above offers the clinician the ability to determine an exact percentile for a child who has a specific score on the Stroop Color-Word Interference Test. However, this method can be prone to human error due to the number of required computations by hand. To enhance user-friendliness, the authors have completed these steps for a range of raw scores based on age, sex, and MLPE and created tables for clinicians to more easily obtain a percentile range/estimate associated with a given raw score on this test. These tables are available by country and type of test in the Appendix. In order to obtain an approximate percentile for the above example (converting a raw score 
Table 4

Final multiple linear regression models for Stroop Interference scores

\begin{tabular}{|c|c|c|c|c|c|c|}
\hline$\overline{\text { Country }}$ & B & Std. Error & $t$ & Sig. & $R^{2}$ & $S D e$ (residual) \\
\hline \multicolumn{7}{|l|}{ Chile } \\
\hline Constant & 2.616 & 0.460 & 5.686 & $<0.001$ & \multirow{2}{*}{0.086} & \multirow[t]{2}{*}{8.449} \\
\hline Age & 0.765 & 0.136 & 5.624 & $<0.001$ & & \\
\hline \multicolumn{7}{|l|}{ Cuba } \\
\hline Constant & -0.183 & 0.632 & -0.289 & 0.773 & \multirow[t]{3}{*}{0.074} & \multirow[t]{3}{*}{8.049} \\
\hline Age & 0.576 & 0.121 & 4.779 & $<0.001$ & & \\
\hline $\mathrm{Age}^{2}$ & 0.105 & 0.040 & 2.660 & 0.008 & & \\
\hline \multicolumn{7}{|l|}{ Ecuador } \\
\hline Constant & -1.632 & 0.796 & -2.050 & 0.041 & \multirow{3}{*}{0.111} & \multirow[t]{3}{*}{6.912} \\
\hline Age & 0.657 & 0.119 & 5.499 & $<0.001$ & & \\
\hline MLPE & 2.196 & 0.927 & 2.368 & 0.019 & & \\
\hline \multicolumn{7}{|l|}{ Guatemala } \\
\hline Constant & -3.051 & 0.566 & -5.394 & $<0.001$ & \multirow[t]{2}{*}{0.028} & \multirow[t]{2}{*}{5.859} \\
\hline $\mathrm{Age}^{2}$ & 0.171 & 0.081 & 2.107 & 0.037 & & \\
\hline \multicolumn{7}{|l|}{ Honduras } \\
\hline Constant & 0.553 & 0.565 & 0.978 & 0.329 & \multirow[t]{3}{*}{0.099} & \multirow[t]{3}{*}{6.890} \\
\hline Age & 0.654 & 0.135 & 4.830 & $<0.001$ & & \\
\hline Sex & -1.884 & 0.836 & -2.255 & 0.025 & & \\
\hline \multicolumn{7}{|l|}{ Mexico } \\
\hline Constant & 1.131 & 0.354 & 3.194 & 0.001 & \multirow[t]{3}{*}{0.087} & \multirow[t]{3}{*}{7.083} \\
\hline Age & 0.647 & 0.073 & 8.909 & $<0.001$ & & \\
\hline MLPE & 1.018 & 0.488 & 2.087 & 0.037 & & \\
\hline \multicolumn{7}{|l|}{ Paraguay } \\
\hline Constant & 2.938 & 0.542 & 5.420 & $<0.001$ & \multirow[t]{2}{*}{0.156} & \multirow[t]{2}{*}{8.707} \\
\hline Age & 1.133 & 0.163 & 6.953 & $<0.001$ & & \\
\hline \multicolumn{7}{|l|}{ Peru } \\
\hline Constant & 1.196 & 0.411 & 2.912 & 0.004 & \multirow[t]{2}{*}{0.094} & \multirow[t]{2}{*}{7.256} \\
\hline Age & 0.710 & 0.125 & 5.699 & $<0.001$ & & \\
\hline \multicolumn{7}{|l|}{ Puerto Rico } \\
\hline Constant & 2.253 & 0.502 & 4.489 & $<0.001$ & \multirow[t]{2}{*}{0.049} & \multirow[t]{2}{*}{6.821} \\
\hline Age & 0.441 & 0.144 & 3.068 & 0.002 & & \\
\hline Spain & & & & & & \\
\hline Constant & -0.029 & 0.435 & -0.067 & 0.947 & 0.112 & 6.774 \\
\hline Age & 0.678 & 0.067 & 10.196 & $<0.001$ & & \\
\hline $\mathrm{Age}^{2}$ & 0.050 & 0.021 & 2.346 & 0.019 & & \\
\hline MLPE & 1.315 & 0.458 & 2.873 & 0.004 & & \\
\hline
\end{tabular}

Note. MLPE: Mean level of parental education.

of 39 on the Stroop Color test for a Guatemalan girl who is 8 years old and whose parent(s) have 10 years of education) using the simplified normative tables provided in the Appendix, the following steps must be followed. (1) First, identify the appropriate table ensuring the appropriate country and test (Stroop Color, Word, Word-Color, and Interference). In this case, the table for Stroop Color score for Guatemala can be found in Table A15. (2) Find the appropriate age of the child, in this case, 8 years old. (3) Next, look in the 8 years' age column to find the approximate location of the raw score obtained on the test. Within the 8 years' column, the score of 39 obtained by this Guatemalan girl corresponds to an approximate percentile of 30 .

The percentile obtained using this user-friendly table sometimes could be slightly different than the hand-calculated, more accurate method (29th vs. 30th) because the user-friendly table is based on a limited number of percentile values. Individual percentiles cannot be presented in these tables due to space limitations. If the exact score is not listed in the column, you must estimate the percentile value from the list of raw scores available.

\section{Discussion}

The purpose of this study was to obtain normative data for the Stroop Color-Word Interference Test for children and adolescents from nine countries in Latin America (Chile, Cuba, Ecuador, Guatemala, Honduras, Mexico, Paraguay, Peru, and Puerto Rico) and Spain. The final regression models for the Stroop Word score explained between $26.3 \%$ and $63.8 \%$ of the variance, for the Stroop Color scores between 
$20.2 \%$ and $53.4 \%$ of the variance, for the Stroop Word-Color score between $26.5 \%$ and $51.8 \%$ of the variance, and finally, for the Stroop Interference scores between $2.8 \%$ and $15.6 \%$ of the variance.

Age was a significant predictor for all four scores of the Stroop Color-Word Interference Test in all countries, except for Guatemala for the Stroop Interference test, in that scores increased linearly as the children's age advanced. This pattern is similar to those reported in previous studies (e.g. Comalli et al., 1962; Ligon, 1932; Martins et al., 2005; Oliveira et al., 2016; Stroop, 1935) and may correlate with the maturation of children (Tamm, Menon, \& Reiss, 2002). Younger children tend to get lower scores than older children in the Stroop Word and Stroop Color test because of their lower reading fluency and color identification, which progressively develops with age (Ligon, 1932). On the other hand, at the same time as reading fluency increases, control mechanisms are developed and are applied to the reader process, allowing a greater inhibition of this automatic process, and consequently, a gradual decrease of interference (Tzelgov, Henik, \& Leiser, 1990). Comalli et al. (1962) reported that the growing development of selective attention allows children to focus on a given task stimulus (e.g. color) despite distraction (the name of color).

In addition to the linear function of age, a significant effect of the quadratic function of age for all countries was observed for the Stroop Word. For the Stroop Color, age quadratic significantly affected score for Ecuador, Mexico, Peru and Spain; and for the Stroop Word Color, quadratic age significantly affected score for Ecuador, Mexico, and Paraguay. Finally, for the Stroop Interference scores it significantly affected for Cuba, Guatemala, and Spain. Van der Elst et al. (2006) also observed a curvilinear effect of age for the Stroop Color-Word Interference Test but with an adult population, in that performance improves from an early age until approximately the age of 24 years, and from this age on, performance starts to decay. These effects are due to a slower rate of reading and naming, and increase interference with aging (Moering, Schinka, Mortimer, \& Graves, 2004; Wright \& Wanley, 2003).

Sex was only significant for the Stroop Word score in Spain, with girls obtaining better results than boys, the Stroop Color score for Mexico, in that boys obtained better results than girls, and the Stroop Interference score for Honduras. There is no consensus in the literature on the influence of sex on Stroop performance. Some studies like Martins et al. (2005) found significant differences in favor of girls in all Stroop scores, while other studies such as Armengol (2002) did not report any differences. The same discrepancies occur in adults, with studies reporting a better performance in women than in men (Moering et al., 2004; Strickland, D'Elia, James, \& Stein, 1997; Van der Elst et al., 2006) while others reported an inexistent effect of sex (Jensen \& Rohwer, 1966; Ligon, 1932; Stroop, 1935).

Parents' education, on the other hand, has proven to be a very important factor when discussing children's cognitive performance (Meador et al., 2011; Schady, 2011). During the last couple of decades, several authors have directed their attention to the influence of family's socioeconomic level in the neurodevelopment of children, finding that language (Eckert, Lombardino, \& Leonard, 2001; Noble, Wolmetz, Ochs, Farah, \& McCandliss, 2006; Raizada, Richards, Meltzoff, \& Kuhl, 2008) and executive functions (Hughes \& Ensor, 2005; Mezzacappa, 2004; Noble, McCandliss, \& Farah, 2007; Sbicigo, Abaid, Dell'Aglio, \& Salles, 2013) are the most affected cognitive processes. Given that the parents' educational level is one of the variables that make up socioeconomic level (Hoff, 2006), it is expected that children whose parent(s) have a higher level of education will obtain better results in tests that measure executive functions such as the Stroop. However, this study is the only one to date that has included the parents' educational level as a predictive variable for the creation of children's normative data for the Stroop Color-Word Interference Test.

\subsection{Limitations and future directions}

Despite the importance of this study, since it is the largest in the world that has been developed for validation and standardization of the Stroop Color-Word Interference Test in Spanish-speaking children, the results of the study should be interpreted in light of the following limitations: This study presents normative data for the Stroop Color-Word Interference for nine countries from Latin America and Spain. For this reason, it is not advisable to use these norms in the pediatric population of those Spanish-speaking countries where the study was not performed. Future studies should be conducted to standardize this test in other Spanish-speaking countries.

Although the norms of the present study could be used by neuropsychologists in other countries to evaluate Spanish-speaking immigrant children from the countries where the sample was collected for this 
study, they should be used with caution since other variables such as level of acculturation, bilingualism, the number of years living in the country, and so on, could influence performance. In addition, the quality of education of both the child and the parent(s) is another aspect that may influence the cognitive performance of children.

On the other hand, it is very important to keep in mind that no clinical diagnosis should be made based solely on the scores of this test. This test should be integrated as part of a much larger battery that evaluates these processes in more detail. Because there are a limited number of tests and norms in Latin America and Spain to evaluate these processes, more efforts should be made in the future to have other similar tools.

Although the size of the sample was adequate in each of the countries where the study was conducted, it is very important to note that only the sample in Chile, Mexico, Paraguay, Puerto Rico, and Spain was obtained from several regions of the country, while in the remaining countries were collected from only one geographic area. Future studies should expand the sample in other geographical areas of these countries with the objective to be able to have a greater representativeness of the sample.

The children who participated in the present study had Spanish as their first language. Although Spanish is the first language of the majority of the population in Latin America and Spain, it is important to keep in mind there is a great cultural and linguistic richness to the point that in many of these countries, sometimes the first language of many children may be completely different from Spanish (e.g., Portuguese, Euskera, Catalan, Guaraní, Maya, Quechua). For this reason, caution should be used when using these norms in children whose first language is not Spanish.

Finally, it is important to keep in mind that the present study was performed with normal healthy population. Therefore, future studies should be performed with clinical population to establish the sensitivity and specificity of this test.

\subsection{Implications and conclusions}

Despite the aforementioned limitations, the present study stands out for being the first to offer normative data for the Stroop Color-Word Interference Test in Spanish-speaking children, taking into account cultural and socio-demographic characteristics. Similarly, the sample of 4,373 children and adolescents from nine countries in Latin America and Spain, make it the largest multicenter study worldwide. In addition, up-to-date approaches have been used for the creation and development of normative data in order to allow more precise calculations, such as the use of multiple regressions and residual values rather than average scores and standard deviations.

The additions of parents' education, as well as the quadratic function of age in the final regression models, are one of the main advantages this study has in comparison to other normative studies where these variables have not been taken into account (e.g. Armengol, 2002; Barbarotto et al., 1998; Lee et al., 2002; Martins et al., 2005; Oliveira et al., 2016). Therefore, the results of this study are expected to contribute to the improvement of quality standards in the neuropsychological evaluation of pediatric population in these countries.

\section{Conflict of interest}

None to report.

\section{Supplementary material}

The supplementary material is available in the electronic version of this article: http://dx.doi.org/10. 3233/NRE-172246.

\section{References}

Aiken, L. S., \& West, S. G. (1991). Multiple regression: Testing and interpreting interactions. Newbury Park, CA: Sage.

Ardila, A. (2007). The impact of culture on neuropsychological test performance. In B. P. Uzzell \& M.O. Ponton (Eds.), International handbook of cross-cultural neuropsychology (pp. 23-44). New York, NY: Psychology Press.

Armengol, C. G. (2002). Stroop test in Spanish: Children's norms. The Clinical Neuropsychologist, 16(1), 67-80.

Assef, E. C., Capovilla, A. G. S., \& Capovilla, F. C. (2007). Computerized Stroop test to assess selective attention in children with attention deficit hyperactivity disorder. Spanish Journal of Psychology, 10, 33-40.

Barbarotto, R., Laiacona, M., Frosio, R., Vecchio, M., Farinato, A., \& Capitani, E. (1998). A normative study on visual reaction times and two Stroop colour-word tests. The Italian Journal of Neurological Sciences, 19(3), 161-170.

Bialystok, E., Luk, G., Peets, K. F., \& Yang, S. (2010). Receptive vocabulary differences in monolingual and bilingual children. Bilingualism: Language and Cognition, 13(4), 525-531.

Brown, L., Sherbenou, R. J. \& Johnsen, S. K. (2009). Test de inteligencia no verbal TONI-2. Madrid: TEA ediciones. 
Castro-Caldas, A., Petersson, K. -M., Reis, A., Stone-Elander, S., \& Ingvar, M. (1998). Learning in childhood determines the functional organisation of the adult brain. Brain, 121, 1053-1063.

Chang, Y. K., Liu, S., Yu, H. H., \& Lee, Y. H. (2012). Effect of acute exercise on executive function in children with attention deficit hyperactivity disorder. Archives of Clinical Neuropsychology, 27(2), 225-237.

Comalli, P. E. Jr., Wapner, S., \& Werner, H. (1962). Interference effects of Stroop Color-Word Test in childhood, adulthood, and aging. Journal of Genetic Psychology, 100(1), 47-53.

Cook, R. D. (1977). Detection of influential observation in linear regression. Technometrics, 19(1), 15-18. doi: $10.2307 / 1268249$

Dodrill, C. B. (1978). A neuropsychological battery for epilepsy. Epilepsia, 19(6), 611-623.

Eckert, M. A., Lombardino, L. J., \& Leonard, C. M. (2001). Planar asymmetry tips the phonological playground and environment raises the bar. Child development, 72(4), 988-1002.

Egner T., \& Hirsch J. (2005). The neural correlates and functional integration of cognitive control in a Stroop task. Neuroimage, 24(2), 539-547.

Esposito, A. G., Baker-Ward, L., \& Mueller, S. T. (2013). Interference suppression vs. response inhibition: An explanation for the absence of a bilingual advantage in preschoolers' Stroop task performance. Cognitive Development, 28(4), 354-363.

Faccioli, C., Peru, A., Rubini, E., \& Tassinari, G. (2008). Poor readers but compelled to read: Stroop effects in developmental dyslexia. Child Neuropsychology, 14, 277-283.

Farah, M. J., Shera, D. M., Savage, J. H., Betancourt, L., Giannetta, J. M., Brodsky, N. L., . . \& Hurt, H. (2006). Childhood poverty: Specific associations with neurocognitive development. Brain research, 1110(1), 166-174.

Ferraro, F. R. (2015). Minority and cross-cultural aspects of neuropsychological assessment: Enduring and emerging trends. New York, NY: Psychology Press.

Gautam, P., Warner, T. D., Kan, E. C., \& Sowell, E. R. (2015). Executive function and cortical thickness in youths prenatally exposed to cocaine, alcohol and tobacco. Developmental Cognitive Neuroscience, 16, 155-165.

Golden, C. J. (2007). Stroop, Test de Colores y Palabras: Manual ( $5^{\circ}$ Edición). Madrid: Tea Ediciones, S.A.

Golden, C. J., \& Freshwater S. M. (2002). Stroop Color and Word Test: Revised examiner's manual. Wood Dale, IL: Stoelting Co.

Golden, C. J., Espe-Pfeifer, P., \& Wachsler-Felder, J. (2000). Neuropsychological interpretation of objective psychological tests. Springer Science \& Business Media.

Harrison, B. J., Shaw, M., Yücel, M., Purcell, R., Brewer, W. J., Strother, S. C., ...\& Pantelis, C. (2005). Functional connectivity during Stroop task performance. Neuroimage, 24(1), 181-191.

Hoff, E. (2006). How social contexts support and shape language development. Developmental Review, 26(1), 55-88.

Hughes, C., \& Ensor, R. (2005). Executive function and theory of mind in 2 year old: A family affair?. Developmental Neuropsychology, 28(2), 645-668.

Jensen, A. R., \& Rohwer, W. D. (1966). The Stroop color-word test: A review. Acta psychologica, 25, 36-93.

Kernan, C. L., Asarnow, R., Siddarth, P., Gurbani, S., Lanphier, E. K., Sankar, R., \& Caplan, R. (2012). Neurocognitive profiles in children with epilepsy. Epilepsia, 53(12), 2156-2163.
Kim, S. J., Park, M. H., Lee, J. W., Chung, N. G., Cho, B., Lee, I. G., \& Chung, S. Y. (2015). Neurocognitive outcome in survivors of childhood acute lymphoblastic leukemia: Experience at a tertiary care hospital in Korea. Journal of Korean Medical Science, 30(4), 463-469.

Kovacs, M. (1992). Children's depression inventory. North Tonawanda, NY: Multi-Health System.

Kutner, M. H., Nachtsheim, C. J., Neter, J., \& Li, W. (2005). Applied linear statistical models (5th ed.). New York: McGraw Hill.

Lai, C. L. E., Lau, Z., Lui, S. S., Lok, E., Tam, V., Chan, Q., .. \&\& Cheung, E. F. (2016). Meta-analysis of neuropsychological measures of executive functioning in children and adolescents with high-functioning autism spectrum disorder. Autism Research.

Lebel, C., Warner, T., Colby, J., Soderberg, L., Roussotte, F., Behnke, M., ...\& Sowell, E. R. (2013). White matter microstructure abnormalities and executive function in adolescents with prenatal cocaine exposure. Psychiatry Research: Neuroimaging, 213(2), 161-168.

Lee, T. M., Yuen, K. S., \& Chan, C. C. (2002). Normative data for neuropsychological measures of fluency, attention, and memory measures for Hong Kong Chinese. Journal of Clinical and Experimental Neuropsychology, 24(5), 615-632.

Lezak, M. D. (1995). Neuropsychological assessment (3rd ed.). New York: Oxford University Press.

Ligon, E. M. (1932). A genetic study of color naming and word reading. The American Journal of Psychology, 44(1), 103-122.

Martins, I. P., Castro-Caldas, A., Townes, B. D., Ferreira, G., Rodrigues, P., Marques, S., .. \& \& Derouen, T. (2005). Age and sex differences in neurobehavioral performance: A study of Portuguese elementary school children. International Journal of Neuroscience, 115(12), 1687-1709.

Max, J. E., Schachar, R. J., Landis, J., Bigler, E. D., Wilde, E. A., Saunders, A. E., . . \& \& Levin, H. S. (2013). Psychiatric disorders in children and adolescents in the first six months after mild traumatic brain injury. The Journal of Neuropsychiatry and Clinical Neurosciences, 25(3), 187-197.

Meador, K. J., Baker, G. A., Browning, N., Clayton-Smith, J., Cohen, M. J., Kalayjian, L. A., ...\& Loring, D. W. (2011). Relationship of child IQ to parental IQ and education in children with fetal antiepileptic drug exposure. Epilepsy \& Behavior, 21(2), 147-152.

Mezzacappa, E. (2004). Alerting, orienting, and executive attention: Developmental properties and sociodemographic correlates in an epidemiological sample of young, urban children. Child Development, 75(5), 1373-1386.

Moering, R. G., Schinka, J. A., Mortimer, J. A., \& Graves, A. B. (2004). Normative data for elderly African Americans for the Stroop color and word test. Archives of Clinical Neuropsychology, 19(1), 61-71.

Moran, L., \& Yeates, K. O. (2011). Stroop Color and Word Test, Children's Version. In Encyclopedia of Clinical Neuropsychology (pp. 2403-2404). Springer New York.

Noble, K. G., McCandliss, B. D., \& Farah, M. J. (2007). Socioeconomic gradients predict individual differences in neurocognitive abilities. Developmental Science, 10(4), 464-480.

Noble, K. G., Wolmetz, M. E., Ochs, L. G., Farah, M. J., \& McCandliss, B. D. (2006). Brain-behavior relationships in reading acquisition are modulated by socioeconomic factors. Developmental Science, 9(6), 642-654. 
Oliveira, R. M., Mograbi, D. C., Gabrig, I. A., \& CharchatFichman, H. (2016). Normative data and evidence of validity for the Rey Auditory Verbal Learning Test, Verbal Fluency Test, and Stroop Test with Brazilian children. Psychology \& Neuroscience, 9(1), 54.

Paulesu, E., Démonet, J.-F., Fazio, F., McCrory, E., Chanoine, V., Brunswick, N., ...\& Frith, U. (2001). Dyslexia: Cultural diversity and biological unity. Science, 291, 2165-2167.

Raizada, R. D., Richards, T. L., Meltzoff, A., \& Kuhl, P. K. (2008). Socioeconomic status predicts hemispheric specialization of the left inferior frontal gyrus in young children. Neuroimage, 40(3), 1392-1401.

Razani, J., Burciaga, J., Madore, M., \& Wong, J. (2007). Effects of acculturation on tests of attention and information processing in an ethnically diverse group. Archives of Clinical Neuropsychology, 22(3), 333-341.

Regard, M. (1984). Cognitive rigidity and flexibility: A neuropsychological study. University of Victoria.

Rivera, D. \& Arango-Lasprilla, J. C. (2017). Methodology for the development of normative data for Spanish Speaking pediatric population. NeuroRehabilitation, 41(3), 581-592.

Rivera, D., Perrin, P. B., Stevens, L. F., Garza, M. T., Weil, C., Saracho, C. P., ...\& García de la Cadena, C. (2015). Stroop color-word interference test: Normative data for the Latin American Spanish speaking adult population. NeuroRehabilitation, 37(4), 591-624.

Rognoni, T., Casals-Coll, M., Sánchez-Benavides, G., Quintana, M., Manero, R. M., Calvo, L., ... \& Peña-Casanova, J. (2013). Estudios normativos españoles en población adulta joven (proyecto NEURONORMA jóvenes): Normas para las pruebas Stroop Color-Word Interference Test y Tower of LondonDrexel University. Neurología, 28(2), 73-80.

Rosselli, M., Ardila, A., Santisi, M. N., del Rosario Arecco, M, Salvatierra, J., Conde, A., \& Lenis, B. (2002). Stroop effect in Spanish- English bilinguals. Journal of the International Neuropsychological, 8(06), 819-827.

Sbicigo, J. B., Abaid, J. L. W., Dell'Aglio, D. D., \& Salles, J. F. D. (2013). Nível socioeconômico e funções executivas em crianças/adolescentes: Revisão sistemática. Arquivos Brasileiros de Psicologia, 65(1), 51-69.

Schady, N. (2011). Parents' education, mothers' vocabulary, and cognitive development in early childhood: Longitudinal evidence from Ecuador. American Journal of Public Health, 101(12), 2299-2307.

Spreen, O. \& Strauss E. (1998). A compendium of neuropsychological tests (2nd ed.). New York: Oxford University Press.

Strauss E., Sherman E., \& Spreen O. (2006). A Compendium of Neuropsychological Tests: Administration, Norms, and Commentary, (3rd ed.). New York: Oxford University Press.

Strickland, T. L., D'elia, L. F., James, R., \& Stein, R. (1997). Stroop color-word performance of African Americans. The Clinical Neuropsychologist, 11(1), 87-90.

Stroop, J. R. (1935). Studies of interference in serial verbal reactions. Journal of Experimental Psychology, 18(6), 643.

Tamm, L., Menon, V., \& Reiss, A. L. (2002). Maturation of brain function associated with response inhibition. Journal of the American Academy of Child \& Adolescent Psychiatry, 41(10), 1231-1238.

Tzelgov, J., Henik, A., \& Leiser, D. (1990). Controlling Stroop interference: Evidence from a bilingual task. Journal of Experimental Psychology: Learning, Memory, and Cognition, 16(5), 760.

Tzelgov, J., Meyer, J., \& Henik, A. (1992). Automatic and intentional processing of numerical information. Journal of Experimental Psychology: Learning, Memory, and Cognition, 18(1), 166.

Van der Elst, W., Van Boxtel, M. P., Van Breukelen, G. J., \& Jolles, J. (2006). The stroop color-word test: Influence of age, sex, and education; and normative data for a large sample across the adult age range. Assessment, 13(1), 62-79.

Wecker, N. S., Kramer, J. H., Wisniewski, A., Delis, D. C., \& Kaplan, E. (2000). Age effects on executive ability. Neuropsychology, 14(3), 409.

Westendorp, M., Hartman, E., Houwen, S., Smith, J., \& Visscher, C. (2014). Specific associations between gross motor skills and executive functioning in children with learning disorders: A longitudinal study. Movement and Cognition, 59.

Wright, B. C., \& Wanley, A. (2003). Adults' versus children's performance on the Stroop task: Interference and facilitation. British Journal of Psychology, 94, 475-485. 